Abstracta Iranica

Revue bibliographique pour le domaine irano-aryen

Volume 34-35-36 | 2017

Comptes rendus des publications de 2011-2013

\title{
Anonyme. Parvandeh vižeh : jahān-e haHāmanešì (3)/ Special dossier : The Achaemenid World (3)
}

\section{Rémy Boucharlat}

\section{OpenEdition}

\section{Journals}

\section{Édition électronique}

URL : http://journals.openedition.org/abstractairanica/42125

DOI : 10.4000/abstractairanica.42125

ISSN : 1961-960X

Éditeur :

CNRS (UMR 7528 Mondes iraniens et indiens), Éditions de l'IFRI

Référence électronique

Rémy Boucharlat, « Anonyme. Parvandeh vižeh : jahān-e hahāmanešī (3)/ Special dossier : The Achaemenid World (3) », Abstracta Iranica [En ligne], Volume 34-35-36 | 2017, document 118, mis en ligne le 30 juillet 2017, consulté le 03 octobre 2020. URL : http://journals.openedition.org/ abstractairanica/42125 ; DOI : https://doi.org/10.4000/abstractairanica.42125

Ce document a été généré automatiquement le 3 octobre 2020.

Tous droits réservés 


\title{
Anonyme. Parvandeh vižeh : jahān-e haH̄ämaneši (3)/Special dossier : The Achaemenid World (3)
}

\author{
Rémy Boucharlat
}

\section{RÉFÉRENCE}

Anonyme. « Parvandeh vižeh : jahān-e haHāmanešī (3)/ Special dossier : The Achaemenid World (3) ». Bāstānpazhuhi, vol. 7, No. 14-15, Spring and Summer 2013, p. 52-148 (en persan, avec résumés en anglais).

1 Les deux premiers volets de ce " Dossier achéménide " étaient surtout des traductions d'articles, parfois anciens, publiés en Occident. Dans celui-ci, 9 des 10 articles ou notes sont des contributions originales par des archéologues iraniens : découvertes récentes, études sur une région ou sur un monument, elles enrichissent l'image de l'occupation à l'époque achéménide, surtout dans le sud-ouest de l'Iran. Du fait des catégories de documents identifiés, surtout des bases de colonnes, cette image concerne principalement l'élite de la société de l'époque achéménide. Les titres sont donnés ici sont ceux des résumés en anglais (p. 4-8).

2 M.J. Ja'fari, « Achaemenid Settlements in Northern Khorāsan, Irān », p. 52-60, présente des sites d'époque achéménide dans la province du Khorasan Shomali et particulièrement celui de Rivi, où des fouilles, commencées en 2012, se poursuivent $p$. 52-60.

3 M.T. Atāyi, Sh. Zāre', E. Yaghmāee, E. Gezelbāsh, « The Site of Ảlakun : A possible Achaemenid road station in Bāsht Plain of Gachsāran ", (p. 61-73 avec nombreuses illustrations), dans la province Kohkiluyeh va Boyer Ahmad, serait une station routière. Dans les années 1990 ont été repérées en surface des bases de colonne campaniformes inachevées (sans décor), surmontées d'un tore. Un survey en 2007 et 2009 a permis de préciser qu'elles appartiennent à deux modules différents 63 et $87 \mathrm{~cm}$ ). Elles étaient 
fondées sur un socle circulaire évidé, par une partie saillante solidaire de la base. Par ailleurs une plaque presque carrée $(128 \times 122 \mathrm{~cm})$ divisée en neuf panneaux chacun remplie par une rosette a pu être un seuil, à titre d'hypothèse. On peut penser aussi à un panneau mural.

A. Parviz, «Tol-e Bābouneh : An Achaemenid Settlement », p. 74-82, mentionne une base de colonne campaniforme décorée de palmette, découverte fortuitement dans un puits, dans la plaine de Cherām, province de Kohkiluyeh va Boyer Ahmad.

5 E. Yaghmāee, « Gouyom and Beizā : Scattered remains of some Achaemenid Structures in Fārs ", p. 83-88, rapporte une série de découvertes de bases de colonnes faites dans les dernières décennies à Gouyom et Tol-e Baizā à quelques dizaines de kilomètres au nord de Shiraz. La plupart des bases sont campaniformes, appartenant à plusieurs types différents, avec palmettes, mais avec ou sans registre d'oves au sommet de celle-ci ; d'autres sont lisses, inachevées ( ?). A noter aussi une plinthe carrée à deux degrés surmontées d'un tore, ainsi que de gros tores circulaires, indépendants de la base. Il est possible que certains profils peu habituels soient post-achéménides. Quoi qu'il en soit, ces documents représentent certainement plusieurs constructions distinctes.

6 M.T. Atāyi, «Band-e Dokhtar : Water Management technology and land use during the Achaemenid Fārs ", p. 89-102, réexamine le barrage en pierre dit de Dorudzan, en amont de la plaine de Persepolis, qui fut déplacé lors de la construction du barrage de Darius dans les années 1960. L'analyse de la stratigraphie de l'emplacement d'origine permet à l'A. de conclure que le contexte est achéménide et post-achéménide et non pas plus tardif. La question est celle de l'utilité de cette construction à cette époque : irriguer une partie de la plaine jusqu'à la zone de Persépolis, comme le proposait W. Sumner? ou bien seulement la zone de 250 ha environ entre les rivières Kur et Bidun, bien en amont de Persépolis, comme le pense l'A., à la suite de M. McNicol.

7 A.A. Asadi \& B. Kaim, « Hunting Scene on an Achaemenid Ceramic Vessel », p. 103-110, développent l'analyse qu'ils avaient donnée de cette étonnante jarre dans la revue ARTA (www.achemenet.com/document/2009.003-Asadi\&Kaim.pdf) retrouvée dans un bâtiment du Tang-i Bolaghi près de Pasargades. Elle est décorée sur l'épaule d'un registre en relief illustrant des scènes de chasse, interprétation assez primitive de représentations fréquentes sur les sceaux des tablettes de Persépolis. Retrouver cette iconographie sur une poterie commune est exceptionnel.

8 A. Mousavi, M.T. Atāyi, « New Findings from Pasargadae and a New Proposition for the Reconstruction of the so-called Zendan-i Soleiman Doorway ». Les AA. analysent quatre fragments d'une épaisse dalle en pierre portant sur une face un cadre saillant décoré de fleurs de lotus. C'est une découverte fortuite (2004), dans le secteur de l'enceinte polygonale, donc à distance de la tour dite Zendan-i Solaiman. Les AA. proposent d'y voir une seconde porte de ce monument), de l'époque de Darius (les blocs sont travaillés au ciseau à dents), remplaçant celle de l'époque de Cyrus (travaillée au pic) dont Ali Sami avaient publié des fragments dans son étude de1956 sur Pasargades ; ils proposent une restitution graphique précise de ces documents.

R. Riyāhiān, " A Look at New Achaemenid/Post Achaemenid Finds from Kerman », p. 118-124, recense des documents achéménides de la province de Kerman, très mal connue pour l'époque achéménide. Des bases de colonnes dont certaines ne rappellent que de très loin les modèles des résidences royales, rhyta de terre cuite dont on connaît l'équivalent dans la région de Jazmourian, mais à l'époque parthe, poteries sans doute 
de différentes périodes. Cette imprécision montre bien que cette immense région soufre d'un déficit de la recherche pour les époques historiques.

10 A.A. Asadi \& T. Hartnell, " Pulvār River Valley Archaeological Survey », p. 125-138, on prospecté la vallée du Pulvār en 2008 et 2009, après bien d'autres archéologues. En dépit de la découverte de sites inconnus jusqu'alors, l'image de l'occupation de cette région proche de Persépolis est celle d'une vallée assez peu densément peuplée.

\section{AUTEURS}

\section{RÉMY BOUCHARLAT}

UMR 5133 CNRS-Université de Lyon 